\title{
Relationship between interpersonal sensitivity and leukocyte telomere length
}

\author{
Akihito Suzuki ${ }^{*}$ D, Yoshihiko Matsumoto ${ }^{1}$, Masanori Enokido ${ }^{1}$, Toshinori Shirata ${ }^{1}$, Kaoru Goto ${ }^{2}$ and Koichi Otani ${ }^{1}$
}

\begin{abstract}
Background: Telomeres are repetitive DNA sequences located at the ends of chromosomes, and telomere length represents a biological marker for cellular aging. Interpersonal sensitivity, excessive sensitivity to the behavior and feelings of others, is one of the vulnerable factors to depression. In the present study, we examined the effect of interpersonal sensitivity on telomere length in healthy subjects.

Methods: The subjects were 159 unrelated healthy Japanese volunteers. Mean age \pm SD (range) of the subjects was $42.3 \pm 7.8$ (30-61) years. Interpersonal sensitivity was assessed by the Japanese version of the Interpersonal Sensitivity Measure (IPSM). Leukocyte telomere length was determined by a quantitative real-time PCR method.

Results: Higher scores of the total IPSM were significantly ( $\beta=-0.163, p=0.038$ ) related to shorter telomere length. In the sub-scale analysis, higher scores of timidity were significantly $(\beta=-0.220, p=0.044)$ associated with shorter telomere length.

Conclusions: The present study suggests that subjects with higher interpersonal sensitivity have shorter leukocyte telomere length, implying that interpersonal sensitivity has an impact on cellular aging.
\end{abstract}

Keywords: Interpersonal sensitivity, IPSM, Telomere length

\section{Background}

The personality trait of interpersonal sensitivity is defined as undue and excessive awareness of, and sensitivity to, the behavior and feelings of others [1]. Individuals with this personality are preoccupied with their interpersonal relationships, vigilant to the behavior and moods of others, and overly sensitive to perceived or actual criticism or rejection and their behavior is modified with other's expectations to minimize the risk of criticism or rejection. It has been widely accepted that interpersonal sensitivity is a risk factor for depression, especially postnatal depression [2, 3], non-melancholic depression [4], and atypical depression [5]. This personality has also been related to bulimic symptomatology in undergraduate students [6], nicotine dependence in a community sample [7], and alcohol dependence in depressive patients [8]. Recent studies show that the function of hypothalamic-pituitary-adrenal (HPA) axis is involved in the characterization of this personality [9-12].

\footnotetext{
* Correspondence: suzukiakihito@hotmail.com

${ }^{1}$ Department of Psychiatry, Yamagata University School of Medicine, 2-2-2

lidanishi, Yamagata 990-9585, Japan

Full list of author information is available at the end of the article
}

Telomeres are repetitive DNA sequences located at the ends of chromosomes and play a crucial role in preventing chromosome fusion and in maintaining genome stability $[13,14]$. Telomere length is maintained by telomerase, a cellular enzyme, in germ cells and stem cells, while most somatic cells have very low telomerase activity, thus leading to telomere length shortening with cellular division [13, 14]. When telomere length reaches a critical point, cellular senescence is triggered, cell division ceases, and the cell dies $[13,14]$. Thus, telomere length represents a biological marker for cellular aging. Previous studies have shown that telomere length is related to coronary heart disease $[15,16]$, cancer $[17,18]$, progression of diabetic nephropathy in patients with type 1 diabetes [19], dementia in post-stroke patients [20], and mortality [21, 22]. Shorter telomere length is also associated with mood disorders, schizophrenia, mild cognitive impairment, and Alzheimer disease [23].

It has been suggested that telomere length is influenced by certain personality traits such as pessimism [24, 25], neuroticism [26], and hostility [27]. We hypothesized that interpersonal sensitivity might be one of the 
factors influencing telomere length; however, there is no study examining the effects of interpersonal sensitivity on telomere length. Therefore, in the present study, we examined the relationship between interpersonal sensitivity and leukocyte telomere length in healthy subjects.

\section{Methods}

Originally, 192 physically healthy Japanese were recruited from hospital staffs. Exclusion criteria were the presence of physical diseases, which was assessed by using the self-reported check sheets for physical diseases and treatments, and the presence of a current or past history of psychiatric disorders according to the Diagnostic and Statistical Manual of Mental Disorders-IV [5]. Psychiatric screening was conducted by interviews by well trained psychiatrists and a questionnaire on psychiatric treatment and diagnosis. Nine cases had psychiatric disorders and 18 had missing data. Data of 6 subjects were excluded due to failure of DNA extraction or PCR amplification. The remaining 159 subject samples were used for analysis. Mean age \pm SD (range) of the subjects was $42.3 \pm 7.8$ (30-61) years. The subject's characteristics are shown in Table 1 . The study protocol was approved by the ethics committee of the Yamagata University School of Medicine. After complete description of the study to the subjects, written informed consent was obtained from all subjects.

Interpersonal sensitivity was measured by the Japanese version of the Interpersonal Sensitivity Measure (IPSM), which has been verified to have high test-retest reliability, item-total correlation, internal consistency, and discriminant validity [28]. The IPSM developed by Boyce and Parker [1] and later modified by Boyce et al. [29] is a selfreport scale with 28 items to assess this personality trait. The IPSM has 4 sub-scales, i.e., interpersonal awareness which refers to vigilance to the behavior and feelings of others, separation anxiety which deals with anxiety about separation from significant others, timidity which assesses lack of assertiveness for fear of upsetting others, and

Table 1 Characteristics of subjects, relative telomere length, and IPSM scores

\begin{tabular}{ll}
\hline Number of subjects $(\mathrm{n})$ & 159 \\
Male/Female ( $\mathrm{n})$ & $83 / 76$ \\
Age (years, mean \pm SD (range)) & $42.3 \pm 7.8$ (30-61) \\
Relative telomere length (z-score, range) & $-2.05-3.54$ \\
IPSM (score, mean \pm SD) & \\
Total & $64.6 \pm 10.7$ \\
Interpersonal awareness & $18.0 \pm 3.5$ \\
Separation anxiety & $17.5 \pm 3.8$ \\
Timidity & $19.6 \pm 2.9$ \\
Fragile inner-self & $9.5 \pm 2.3$ \\
\hline IPSM Interpersonal Sensitivity Measure, SD Standard deviation
\end{tabular}

IPSM Interpersonal Sensitivity Measure, SD Standard deviation fragile inner-self which identifies difficulty with selfdisclosure for fear of rejection. In the present sample, the values of Cronbach's $\alpha$ for total IPSM, interpersonal awareness, separation anxiety, timidity, and fragile innerself were $0.911,0.818,0.817,0.674$, and 0.706 , respectively, suggesting that the magnitudes of these values were considered to be satisfactory.

Ten $\mathrm{ml}$ of blood was obtained from subjects' median vein in a EDTA-containing tube, and genomic DNA was extracted from peripheral leukocytes using a QIAamp DNA Blood Kit (Qiagen, Tokyo, Japan), and was stored at $-80{ }^{\circ} \mathrm{C}$ before PCR amplification. Leukocyte relative telomere length, assessed by a ratio of telomere/single copy gene (36B4) with the mean data from the triplicate runs, was determined by a quantitative real-time PCR method of Cawthon [30] with several modifications [31]. The intra- and inter-assay coefficients of variation for the telomere reaction were $1.67 \%$ and $1.71 \%$, respectively, and those for the 36B4 reaction were $3.19 \%$ and $5.06 \%$, respectively. Relative telomere length was expressed as a standardized z-score in this study, since a standard curve to perform quantification of each DNA sample was created from DNA dilution of a subject, i.e., obtained telomere length was expressed as relative length to the subject. The telomere length was determined by researchers who were blind to the results of the IPSM.

In our previous studies, relative telomere length was influenced by gender and age [31, 32]. Thus, the effects of the total and 4 sub-scale scores of the IPSM on telomere length were tested by the multiple regression analysis with telomere length as a dependent variable and with the IPSM scores, age, and gender as independent variables. No elimination technique was adopted, and all the independent variables were used. A dummy variable was used for gender (female $=0$, male $=1$ ). Sex differences in the IPSM scores and telomere length were tested by the Student t-test. Normality of data distribution was checked using the Kolmogorov-Smirnov test. The Smirnov-Grubbs' test was used to evaluate outliers of telomere length. All statistical analyses were performed by SPSS $14.0 \mathrm{~J}$ for Windows (SPSS Japan Inc., Tokyo, Japan), and a $p$ value of less than 0.05 (two-tailed) was regarded as significant.

\section{Results}

The effects of the total and 4 sub-scale scores of the IPSM on telomere length are shown in Table 2 and Table 3, respectively. The data for telomere length was normally distributed $(p=0.079)$, and did not involve outliers. In the present sample, there were no sex differences in the IPSM scores (male vs. female, mean \pm SD: Total IPSM, $64.0 \pm 9.1$ vs. $65.2 \pm 12.2, p=0.494$; interpersonal awareness, $17.7 \pm 3.3$ vs. $18.3 \pm 3.8, p=0.304$; separation anxiety, $17.5 \pm 3.6$ vs. $17.6 \pm 4.1, p=0.877$; timidity, $19.6 \pm 2.6$ vs. $19.6 \pm 3.2, p=0.997$; fragile 
Table 2 Effects of the total IPSM scores, age, and sex on relative telomere length

\begin{tabular}{llc}
\hline & \multicolumn{2}{l}{ Relative telomere length } \\
\cline { 2 - 3 } & $\beta$ & $p$ \\
\hline Total IPSM & -0.163 & 0.038 \\
Age & -0.169 & 0.031 \\
Sex & -0.126 & 0.106 \\
Multiple correlation coefficient & \multicolumn{2}{c}{$R=0.264, p=0.011$} \\
\hline
\end{tabular}

IPSM Interpersonal Sensitivity Measure

The multiple regression analysis was performed with telomere length as a dependent variable and with the IPSM scores, age, and gender as independent variables

inner-self, $9.3 \pm 1.7$ vs. $9.8 \pm 2.7, p=0.158)$ nor telomere length $(-0.11 \pm 0.93$ vs. $0.12 \pm 1.06, p=0.147)$.

Higher scores of the total IPSM $(\beta=-0.163, p=0.038)$ were significantly related to shorter telomere length (Table 2 and Fig. 1). Age was negatively correlated with telomere length $(\beta=-0.169, p=0.031)$ (Table 2$)$.

In the sub-scale analysis, higher scores of timidity $(\beta=-0.220, p=0.044)$ were associated with shorter telomere length, while the scores of interpersonal awareness, separation anxiety, and fragile inner-self were not related to telomere length (Table 3$)$. Age was negatively correlated with telomere length $(\beta=-0.159, p=0.042)$ (Table 3 ).

\section{Discussion}

This study was the first attempt to examine the relationship between interpersonal sensitivity and telomere length. In the present study, there was a significant negative correlation between the total IPSM scores and leukocyte telomere length, i.e., the subjects who have excessive sensitivity to other's behaviors and feelings were more likely to have shorter telomere length. The present result is in line with the previous study reporting that high neuroticism, which is related to interpersonal sensitivity [33], was associated with shorter telomere length [26].

Table 3 Effects of the 4 sub-scale scores of the IPSM, age, and sex on relative telomere length

\begin{tabular}{llc}
\hline & \multicolumn{2}{l}{ Relative telomere length } \\
\cline { 2 - 3 } & $\beta$ & $p$ \\
\hline Interpersonal awareness & -0.053 & 0.656 \\
Separation anxiety & 0.055 & 0.656 \\
Timidity & -0.220 & 0.044 \\
Fragile inner-self & 0.018 & 0.874 \\
Age & -0.159 & 0.042 \\
Sex & -0.119 & 0.133 \\
Multiple correlation coefficient & \multicolumn{2}{c}{$R=0.301, p=0.024$}
\end{tabular}

IPSM Interpersonal Sensitivity Measure

The multiple regression analysis was performed with telomere length as a dependent variable and with the IPSM scores, age, and gender as independent variables

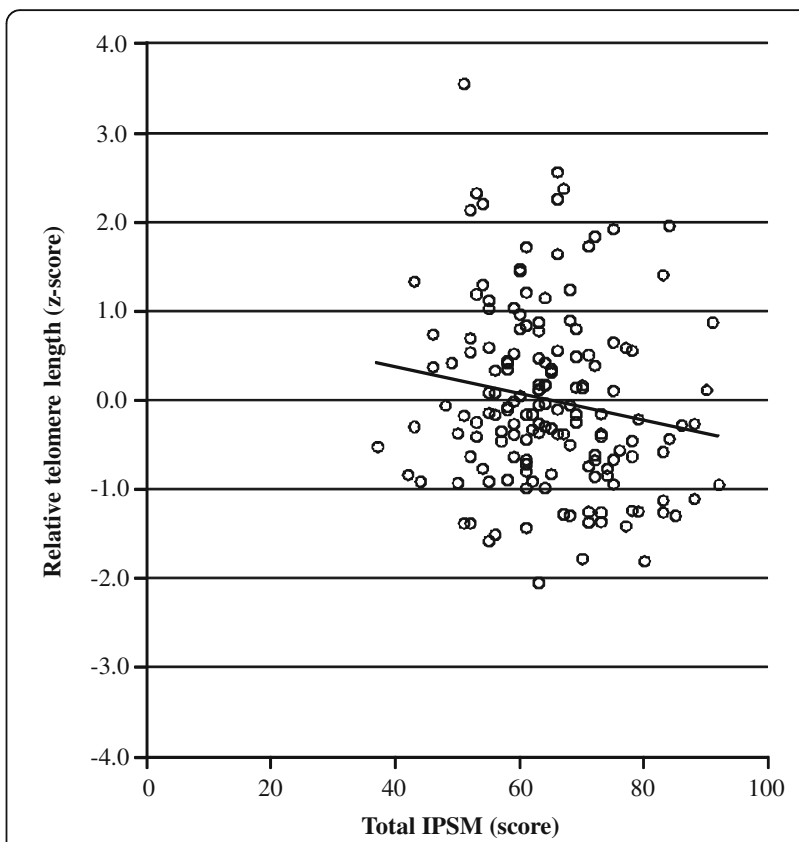

Fig. 1 Relationship between interpersonal sensitivity and telomere length. IPSM; Interpersonal Sensitivity Measure

Several mechanism(s) might explain the association between interpersonal sensitivity and telomere length observed in the present study. Firstly, it has been reported that high interpersonal sensitivity is associated with health-harming behaviors such as bulimic behavior [6], nicotine dependence [7], and alcohol dependence [8]. These behaviors have been associated with telomere length shortening [14], thus high interpersonal sensitivity may influence telomere shortening through these health-harming behaviors. Secondly, it has been reported that subjects with high levels of interpersonal sensitivityrelated traits such as neuroticism and rejection sensitivity have an increased HPA activity [11, 12, 34], although the finding is inconsistent $[9,10]$. An in vitro study showed that exposure of human T lymphocytes to cortisol caused a reduction in telomerase activity [35], and in vivo, elevated urinary nocturnal cortisol levels were associated with shorter telomere length in healthy women [36]. Therefore, it is possible that the association between high interpersonal sensitivity and short telomere length is mediated by elevated cortisol levels.

There are several limitations in the present study. Firstly, the present study was a cross-sectional design, i.e., interpersonal sensitivity and telomere length were assessed simultaneously. Thus, the causal relationship between interpersonal sensitivity and telomere length remains unclear. Secondly, the sample size of the present study was relatively small. In addition, all subjects were Japanese hospital staffs, suggesting that replication study is needed with large number of subjects from general populations or other ethnic 
groups. Thirdly, the present study did not assess other factors which may influence telomere length, e.g., body mass index, childhood maltreatment, socioeconomic status, physical activity [14], and current life stress [37]. In addition, although screening of psychiatric diseases was performed by self-report and by interviews, the possibility that sub-threshold disorders such as cigarettes and alcohol uses and unhealthy eating might affect telomere length in the present sample cannot be excluded entirely. Therefore, in further studies on the relationship between telomere length and interpersonal sensitivity, the assessment of these factors is needed.

\section{Conclusion}

The present study suggests that subjects with higher interpersonal sensitivity have shorter leukocyte telomere length, implying that interpersonal sensitivity has an impact on cellular aging.

\section{Abbreviations}

HPA: Hypothalamic-pituitary-adrenal; IPSM: Interpersonal Sensitivity Measure

\section{Acknowledgements}

None.

\section{Funding}

This study was supported by funding from the Ministry of Education, Culture, Sports, Science and Technology of Japan.

\section{Availability of data and materials}

The datasets generated and/or analyzed during the current study are not publicly available because the authors are not allowed to publish the raw data of subject's genetic information by the ethics committee of the Yamagata University School of Medicine. Data are however available from the corresponding author upon reasonable request.

\section{Authors' contributions}

AS conceptualized and designed the study, collected and interpreted the data, and drafted the manuscript. KO designed the study, collected and analyzed the data, and modified the manuscript. YM, ME, TS, and KG collected the data. All authors read and approved the final manuscript.

\section{Ethics approval and consent to participate}

The study protocol was approved by the ethics committee of the Yamagata University School of Medicine. After complete description of the study to the subjects, written informed consent was obtained from all subjects.

\section{Consent for publication}

Consent to publish is not required.

\section{Competing interests}

All authors declare that they have no competing interests.

\section{Publisher's Note}

Springer Nature remains neutral with regard to jurisdictional claims in published maps and institutional affiliations.

\section{Author details}

${ }^{1}$ Department of Psychiatry, Yamagata University School of Medicine, 2-2-2 lidanishi, Yamagata 990-9585, Japan. ²Department of Anatomy and Cell Biology, Yamagata University School of Medicine, 2-2-2 lidanishi, Yamagata 990-9585, Japan.
Received: 20 April 2016 Accepted: 1 October 2017

Published online: 10 October 2017

\section{References}

1. Boyce P, Parker G. Development of a scale to measure interpersonal sensitivity. Aust N Z J Psychiatry. 1989;23:341-51.

2. Boyce P, Parker G, Barnett B, Cooney M, Smith F. Personality as a vulnerability factor to depression. Br J Psychiatry. 1991;159:106-14.

3. Evans J, Heron J, Lewis G, Araya R, Wolke D. Negative self-schemas and the onset of depression in women: longitudinal study. Br J Psychiatry. 2005;186:302-7.

4. Boyce P, Hickie I, Parker G, Mitchell P, Wilhelm K, Brodaty H. Specificity of interpersonal sensitivity to non-melancholic depression. J Affect Disord. 1993;27:101-5.

5. American Psychiatric Association. Diagnostic and Statistical Manual of Mental Disorders. 4th ed. Washington, DC: American Psychiatric Association; 1994.

6. Hamann DM, Wonderlich-Tierney AL, Vander Wal JS. Interpersonal sensitivity predicts bulimic symptomatology cross-sectionally and longitudinally. Eat Disord. 2009;10:125-7.

7. Brook JS, Zhang C, Brook DW, Koppel J, Whiteman M. Psychosocial predictors of nicotine dependence among women during their mid-sixties. Am J Addict. 2012;21:302-12

8. Rae AM, Joyce PR, Luty SE, Mulder RT. The effect of a history of alcohol dependence in adult major depression. J Affect Disord. 2002;70:281-90.

9. Tops M, Riese H, Oldehinkel AJ, Rijsdijk FV, Ormel J. Rejection sensitivity relates to hypocortisolism and depressed mood state in young women. Psychoneuroendocrinology. 2008:33:551-9.

10. Hori H, Ozeki Y, Teraishi T, Matsuo J, Kawamoto Y, Kinoshita Y, Suto S, Terada S, Higuchi T, Kunugi H. Relationships between psychological distress, coping styles, and HPA axis reactivity in healthy adults. J Psychiatr Res. 2010;44:865-73.

11. Stroud LR, Salovey $P$, Epel ES. Sex differences in stress responses: social rejection versus achievement stress. Biol Psychiatry. 2002;52:318-27.

12. Blackhart GC, Eckel LA, Tice DM. Salivary cortisol in response to acute social rejection and acceptance by peers. Biol Psychol. 2007:75:267-76.

13. Blackburn EH. Switching and signaling at the telomere. Cell. 2001;106:661-73.

14. Mather KA, Jorm AF, Parslow RA, Christensen $\mathrm{H}$. Is telomere length a biomarker of aging? A review. J Gerontol A Biol Sci Med Sci. 2011;66:202-13.

15. Brouilette SW, Moore JS, MCMahon AD, Thompson JR, Ford I, Shepherd J, Packard CJ, Samani NJ. West of Scotland Coronary Prevention Study Group: Telomere length, risk of coronary heart disease, and statin treatment in the West of Scotland Primary Prevention Study: a nested case-control study. Lancet. 2007;369:107-14.

16. Haycock PC, Heydon EE, Kaptoge S, Butterworth AS, Thompson A, Willeit P. Leucocyte telomere length and risk of cardiovascular disease: systematic review and meta-analysis. BMJ. 2014:349:94227.

17. Ma H, Zhou Z, Wei S, Liu Z, Pooley KA, Dunning AM, Svenson U, Roos G, Hosgood HD III, Shen M, Wei Q. Shortened telomere length is associated with increased risk of cancer: a meta-analysis. PLoS One. 2011;6:e20466.

18. Sanchez-Espiridion B, Chen M, Chang JY, Lu C, Chang DW, Roth JA, Wu X, $\mathrm{Gu}$ J. Telomere length in peripheral blood leukocytes and lung cancer risk: a large case-control study in Caucasians. Cancer Res. 2014;74:2476-86.

19. Fyhrquist F, Tiitu A, Saijonmaa O, Forsblom C, Groop PH. FinnDiane Study Group: Telomere length and progression of diabetic nephropathy in patients with type 1 diabetes. J Intern Med. 2010;267:278-86.

20. Martin-Ruiz C, Dickinson HO, Keys B, Rowan E, Kenny RA, Von Zglinicki T. Telomere length predicts poststroke mortality, dementia, and cognitive decline. Ann Neurol. 2006;60:174-80.

21. Cawthon RM, Smith KR, O'Brien E, Sivatchenko A, Kerber RA. Association between telomere length in blood and mortality in people aged 60 years or older. Lancet. 2003:361:393-5.

22. Rode L, Nordestgaard BG, Bojesen SE. Peripheral blood leukocyte telomere length and mortality among 64,637 individuals from the general population. J Natl Cancer Inst. 2015;107:djv074

23. Price $L H$, Kao HT, Burgers DE, Carpenter LL, Tyrka AR. Telomeres and earlylife stress: an overview. Biol Psychiatry. 2012;73:15-23.

24. O'Donovan A, Lin J, Tillie J, Dhabhar FS, Wolkowitz OM, Blackburn EH, Epel ES. Pessimism correlates with leukocyte telomere shortness and elevated interleukin-6 in post-menopausal women. Brain Behav Immun. 2009;23:446-9.

25. Ikeda A, Schwartz J, Peters JL, Baccarelli AA, Hoxha M, Dioni L, Spiro A, Sparrow D, Vokonas $P$, Kubzansky LD. Pessimistic orientation in relation to telomere length in older men: the VA normative aging study. Psychoneuroendocrinology. 2014;42: $68-76$. 
26. van Ockenburg $S L$, de Jonge P, van der Harst P, Ormel J, Rosmalen JG. Does neuroticism make you old? Prospective associations between neuroticism and leukocyte telomere length. Psychol Med. 2014;44:723-9.

27. Brydon L, Lin J, Butcher L, Hamer M, Erusalimsky JD, Blackburn EH, Steptoe A. Hostility and cellular aging in men from the Whitehall II cohort. Biol Psychiatry. 2012;71:767-73.

28. Kuwabara H, Sakado K, Uehara T, Sakado M, Sato T, Someya T. The Japanese version of Interpersonal Sensitivity Measure: its reliability and validity. Seishinkashindangaku. 1999;10:333-41. (in Japanese)

29. Boyce P, Harris M, Silove D, Morgan A, Wilhelm H, Hadzi-Pavlovic D. Psychosocial factors associated with depression: A study of socially disadvantaged women with young children. J Nerv Ment Dis. 1998;186:3-11.

30. Cawthon RM. Telomere measurement by quantitative PCR. Nucleic Acids Res. 2002;30:e47.

31. Sadahiro R, Suzuki A, Enokido M, Matsumoto Y, Shibuya N, Kamata M, Goto K, Otani K. Relationship between leukocyte telomere length and personality traits in healthy subjects. Eur Psychiatry. 2015;30:291-5.

32. Enokido M, Suzuki A, Sadahiro R, Matsumoto Y, Kuwahata F, Takahashi N, Goto K, Otani K. Parental care influences leukocyte telomere length with gender specificity in parents and offsprings. BMC Psychiatry. 2014;14:277.

33. Lee KU, Jung NY, Rauch SA, Chae JH, Lee HK, Kweon YS, Lee CT. Psychometric properties of the Korean version of the Interpersonal Sensitivity Measure (IPSM-K). Compr Psychiatry. 2013;54:918-24.

34. Portella MJ, Harmer CJ, Flint J, Cowen P, Goodwin GM. Enhanced early morning salivary cortisol in neuroticism. Am J Psychiatry. 2005;162:807-9.

35. Choi J, Fauce SR, Effros RB. Reduced telomerase activity in human T lymphocytes exposed to cortisol. Brain Behav Immun. 2008;22:600-5.

36. Epel ES, Lin J, Wilhelm FH, Wolkowitz OM, Cawthon R, Adler NE, Dolbier C, Mendes WB, Blackburn EH. Cell aging in relation to stress arousal and cardiovascular disease risk factors. Psychoneuroendocrinology. 2006;31:277-87.

37. Epel ES, Blackburn EH, Lin J, Dhabhar FS, Adler NE, Morrow JD, Cawthon RM. Accelerated telomere shortening in response to life stress. Proc Natl Acad Sci U S A. 2004:101:17312-5.

\section{Submit your next manuscript to BioMed Central and we will help you at every step:}

- We accept pre-submission inquiries

- Our selector tool helps you to find the most relevant journal

- We provide round the clock customer support

- Convenient online submission

- Thorough peer review

- Inclusion in PubMed and all major indexing services

- Maximum visibility for your research

Submit your manuscript at www.biomedcentral.com/submit

) Biomed Central 